\title{
Experimental
}

$\mathrm{C}_{60}$ was purchased from MER corporation (99.5+\%). 5-Bromobarbituric acid was prepared according to a literature procedure. ${ }^{1}$ MALDI-MS spectra were acquired using a TofSpec Maldi-Tof mass spectrometer from Micromass (Manchester, UK). The instrument is equipped with a pulsed $\mathrm{N}_{2}$ laser (337 nm, 4 ns pulse width) and a time-delayed extracted ion-source. Spectra were recorded in the positive-ion mode using the reflectron and with an accelerating voltage of $20 \mathrm{kV}$. A sulfur matrix solution was prepared by dissolving $10 \mathrm{mg}$ of elemental sulfur in $1 \mathrm{~mL}$ of THF and combining this with a solution of sample $(1 \mathrm{mg} / \mathrm{mL})$ in a ratio of $10: 1, \mathrm{v} / \mathrm{v}$. One to two microlitres were deposited onto the sample target, which was vacuumdried. LSIMS-HRMS data were determined on a Micromass Autospec mass spectrometer arranged in an EBE geometry. The instrument was operated at $8 \mathrm{kV}$ accelerating voltage in positive mode. The cesium gun was set to $35 \mathrm{keV}$ energy and $1 \mathrm{LL}$ of sample was mixed in the tip of the probe with a dithiothritol/dithioerythritol matrix. NMR spectra were recorded on a Bruker DPX $400 \mathrm{MHz}$ spectrometer. HPLC analysis was performed on an Agilent 1100 series with a Kromasil silica stationary phase ( 5 micron particle size; $10 \mathrm{~nm}$ pore size). Samples $\left(1 \mathrm{~mL}\right.$ at $\left.[\mathbf{1}]=[\mathbf{2}]=5 \times 10^{-4} \mathrm{M}\right)$ for irradiation experiments were prepared in Pyrex tubes that were degassed by three freeze-pump-thaw cycles and sealed. The setup is composed of a $450 \mathrm{~W}$ high-pressure (Hanovia) mercury arc lamp in a water-cooled Pyrex immersion well. A merry-go-round apparatus was used to ensure uniform irradiation of the samples. The entire setup was immersed in a water bath to filter IR radiation and thermostat the samples.

\section{Synthesis of 1}

$\mathrm{C}_{60}(100 \mathrm{mg})$ and 5-bromobarbituric acid $(28.7 \mathrm{mg})$ were dissolved in toluene:DMSO (95:5, $\mathrm{v} / \mathrm{v}, 150 \mathrm{~mL}$ ). After degassing for $15 \mathrm{~min}$, DBU (28 $\square \mathrm{L}$ ) was added and the color changed immediately from purple to dark red. After stirring for $2 \mathrm{hr}$, the organic phase was removed under reduced pressure. Purification was carried out by column chromatography on silica gel to give $58 \mathrm{mg}$ of $\mathbf{1}$ as a brown solid (50\%).

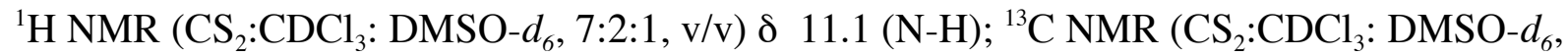
$7: 2: 1, \mathrm{v} / \mathrm{v}) \square 163.9,161.1,151.3,149.1,148.5,147.6,146.8,146.7,146.6,146.4,145.8$, $145.7,145.6,145.3,144.9,144.8,144.4,143.4,143.1,142.6,142.1,141.6,140.5,140.1$, 138.7, 137.8, 135.5, 132.8, 130.9, 129.4, 128.6, 128.4, 125.7.

LSIMS-HRMS. Calc. for $\mathrm{C}_{64} \mathrm{H}_{3} \mathrm{~N}_{2} \mathrm{O}_{3}\left(\mathrm{M}+\mathrm{H}^{+}\right)$: 847.014367 . Found: 847.016310

\section{References}

1 Bright, R.; Coote, S. J.; Freeman, S.; Hayes, D.; Smith, G.; Tapolczay D. Syn. Comm. 1996, 26, 4195. 


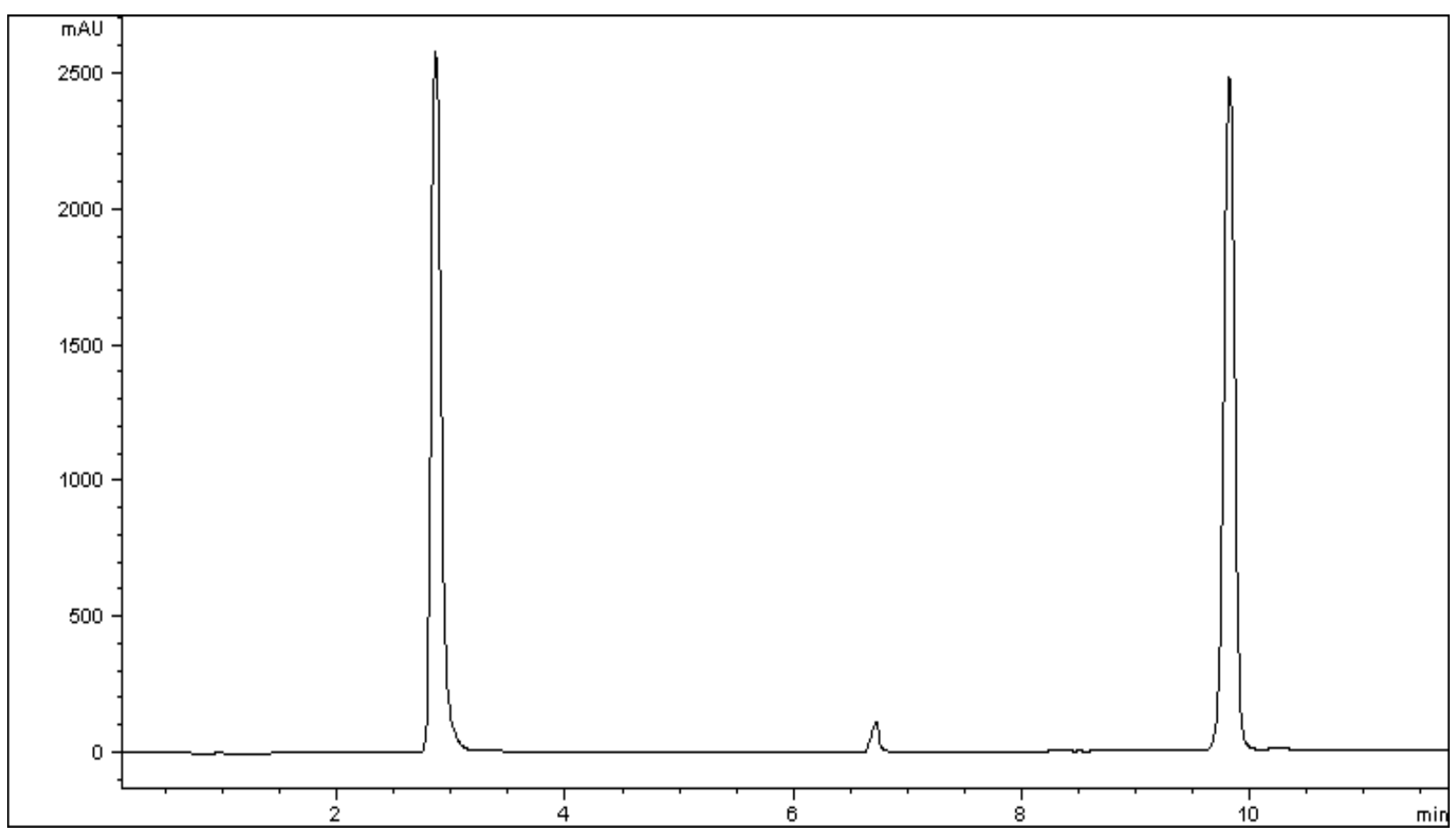

Figure S1. HPLC analysis of crude reaction mixture after $2 \mathrm{hr}$ showing $\mathrm{C}_{60}\left(\mathrm{R}_{\mathrm{t}}=2.8 \mathrm{~min}\right)$ and $1\left(R_{t}=9.8 \mathrm{~min}\right)$. Monitoring at $340 \mathrm{~nm}$. 